\title{
DETERMINANTS OF DAIRY CONSUMPTION EXPENDITURE IN URBAN COMMUNITIES OF SOUTHERN GHANA
}

\author{
R. Aidoo, G.K Nurah, S.C. Fialor and K. Ohene-Yankyera \\ ${ }^{1}$ Department of Agricultural Economics, Agribusiness and Extension, \\ Kwame Nkrumah University of Science \& Technology, Kumasi, Ghana
}

\begin{abstract}
The main purpose of the study was to examine the level of household expenditure on dairy products and to identify the principal factors that influence the level of consumption expenditure on dairy products across households in Accra and Kumasi. Structured questionnaire was used to elicit primary information from a total of 303 households through a multi-stage sampling approach. The double logarithmic multiple regression model was found to be the most suitable functional form and was thus used to examine the major determinants of household dairy consumption expenditure patterns. The principal determinants of aggregate dairy consumption expenditure were identified as income level of household head, distance from home to purchase point and the level of urbanization of consumer's home location. The study revealed that the elasticity of expenditure on dairy products (i.e. evaporated milk and raw fresh milk) with respect to own price is unity. Elasticity of expenditure with respect to income level and prices of substitutes was found to be less than unity. It became evident from the study that raw fresh milk is an inferior commodity in Ghana. However, evaporated milk was found to be a normal commodity.
\end{abstract}

Keywords: Dairy products, consumption expenditure, elasticity, double logarithmic regression model, multi-stage sampling.

\section{INTRODUCTION}

Dairy products constitute an important part of the diet in many households. The food group includes a wide variety of food items all based on some kind of milk. Commonly used dairy products in Ghana include tinned evaporated milk, condensed milk, powdered milk, raw fresh milk, yoghurt, ice cream, imported cheese, local cheese (wagashi) and butter. The total milk consumption (as fluid milk and processed products) per person varies widely from highs in Europe and North America to lows in Asia and Africa. However, as the various regions of the world become more integrated through travel and migration, these trends are changing, a factor which needs to be considered by product developers and marketers of dairy 
products in various countries of the world (Nutrition Society, 2002). Recent attempts at promoting the production and marketing of dairy products in Ghana have been made without recourse to consumer behaviour analysis. It is instructive to note that examination of the structural relationships underlying dairy consumption expenditure in Ghana has received little, if any, attention. The existing knowledge gap makes it extremely difficult for stakeholders in the dairy industry to develop effective marketing strategies and to make deliberate policy interventions to promote and sustain the growth of the infant Ghanaian dairy industry. It was therefore imperative to conduct an empirical research to bring the principal determinants of dairy consumption expenditure to the fore. The development of the dairy industry might unlock its potential to contribute to the development of Ghana through employment generation, reduction in foreign exchange for importing dairy products, and improved nutritional and health status of the people of Ghana. Consumer purchases and spending patterns are influenced by personal, household and product characteristics as well as economic, situational and cultural factors (Jerome and Perreault, 1991; Jaffee and Morton, 1995; Walton and Wykoff, 1998).

The objectives of the study were to estimate the monthly household consumption expenditure on dairy products for various consumer groups; and examine the influence of personal, cultural and socio-economic factors on household dairy consumption expenditure.

\section{RESEARCH METHODOLOGY The Empirical Model}

Most empirical studies on consumption demand have tended to focus on nonlinear specifications. Asenso-Okyere et al. (1997) used the double logarithmic function to find the determinants of household nutritional intake in Ghana with satisfactory results. Deaton and Muellbauer (1980) revealed that the double $\log$ functional form is the most common specification for consumption ex- penditure studies. The advantage with this specification is that the estimated parameters can be interpreted as elasticities or propensities. There are several weaknesses in the linear expenditure system that makes it unattractive in applied work. As the name indicates, the demand functions are linear in expenditure and accordingly, Engel's law (which posits that there is a nonlinear relationship between income and demand for commodities) cannot hold. On the basis of the literature reviewed (Deaton and Muellbauer, 1980; AsensoOkyere et al., 1997), the double logarithmic model was adopted for this study. The implicit form of the double logarithmic model was specified as:

C. $E_{i}=f\left(X_{1}, X_{2}, \ldots, X_{12}\right)+m_{i}$;

where:

C. $E_{\mathrm{i}}=$ Monthly household consumption expenditure on dairy product $i$,

$\mathrm{X}_{1}=$ Income level of household head, $\mathrm{X}_{2}=$ Age of household head, $\mathrm{X}_{3}=$ Gender of household head, $\mathrm{X}_{4}=$ Educational level of household head, $\mathrm{X}_{5}=$ Number of dairy product consumers in household; $\mathrm{X}_{6}=$ Price of product; $\mathrm{X}_{7}=$ Price of substitute product; $\mathrm{X}_{8}=$ Degree of urbanization of consumer's location; $\mathrm{X}_{9}=$ Ethnic affiliation of consumer; $\mathrm{X}_{10}=$ Religious affiliation of consumer, $X_{11}=$ Distance from consumer's home to purchase point, $\mathrm{X}_{12}=$ Storage of dairy products (whether a consumer stores dairy products or not); and $\mathrm{m}_{\mathrm{i}}=$ Random Variable/Disturbance term.

The double logarithmic model has the following mathematical specification:

$\log$ C. $E_{i}=\log A+b_{1} \log X_{1}+b 2 \log X_{2}+\ldots+$ b12 $\log X_{12}+\mu_{i}$

$\log A$ is the intercept of the consumption function. This shows the autonomous expenditure level on diary products. Qualitative variables such as sex, ethnic affiliation, religion, level of urbanization, product type consumed and storage of dairy products were included in the model as dummy variables (see appendix for variable defi- 
nition). The regression analysis was done in two stages. In the first stage the model was run with monthly aggregate household expenditure on all dairy products as dependent variable. In the second stage, the regression analysis was conducted for raw fresh milk and evaporated milk. In the aggregate model however such variables as price of product and prices of substitute products could not be captured because of aggregation problem.

\section{Data Type, Source and Sampling}

Primary data was obtained from household heads through interviews with the use of standardized structured questionnaire.

Accra and Kumasi were purposively selected for the study in view of the high concentration of dairy products and dairy consumers in these areas. Also, these are the areas in Ghana where the prospects of dairy production and marketing look very bright. A multi-stage approach was followed during sampling. A number of communities were purposively selected as clusters. The cluster sampling was followed by quota sampling where quotas were given to the selected communities based on the concentration of dairy product consumers in these communities. Communities selected included Ejura, Mampong, Kintampo, Buipe and Kumasi. For the Accra zone, Adenta, Kaneshie, Madina, Nima, Agbogboloshie, Cantonments and
Accra Central communities were chosen for the conduct of the survey. Within these selected communities, systematic random sampling method was adopted in selecting the respondent households. Moving from one end of the community to the other, every $5^{\text {th }}$ house was selected for interview. In all, three hundred and three (303) respondents were selected from the study communities for the survey.

\section{RESULTS AND DISCUSSION \\ Distribution of dairy product consumers by income level}

Respondents sampled for the study fall within different income categories. It may be evident from Table 1 that $79 \%$ of the consumers had monthly incomes below $₫ 301,000$. This implies that majority of dairy product consumers were low-income earners.

\section{Dairy product type consumed}

The distribution of consumers by product type consumed is shown in Table 2. Eighty-nine percent $(89 \%)$ of dairy product consumers patronized tinned evaporated milk, followed by yoghurt, powdered milk and raw fresh milk. Imported Cheese, Ultra Heated (UHT) milk and boiled fresh milk were the least consumed diary products in Ghana.

Table 1: Distribution of respondents by income group

\begin{tabular}{lrrr}
\hline $\begin{array}{c}\text { Monthly income } \\
\left(\boldsymbol{c}^{\prime} \mathbf{0 0 0}\right)\end{array}$ & Frequency & Percent & Cum. Percent \\
\hline$\leq 100$ & 54 & 17.82 & 17.82 \\
$101-200$ & 115 & 37.95 & 55.77 \\
$201-300$ & 70 & 23.10 & 78.87 \\
$301-400$ & 34 & 11.22 & 90.09 \\
$401-500$ & 11 & 3.63 & 93.72 \\
$501-600$ & 10 & 3.30 & 97.02 \\
$>600$ & 9 & 2.98 & 100.00 \\
Total & $\mathbf{3 0 3}$ & $\mathbf{1 0 0 . 0 0}$ & - \\
\hline
\end{tabular}

Source: Field Survey, 2001 
Table 2: Distribution of Respondents by dairy product Type consumed

\begin{tabular}{lcll}
\hline Dairy Product Type & Frequency $(\mathbf{N}=\mathbf{3 0 3})$ & Percent & Rank* \\
\hline Raw fresh milk & 135 & 44.55 & 4 \\
Boiled milk & 23 & 7.59 & 11 \\
Fermented milk & 70 & 23.10 & 8 \\
Condensed milk & 60 & 19.80 & 9 \\
Evaporated milk & 270 & 89.12 & 1 \\
Powdered milk & 209 & 68.98 & 3 \\
Imported cheese & 13 & 4.29 & 12 \\
UHT milk & 30 & 9.90 & 10 \\
Yoghurt & 258 & 85.15 & 2 \\
Ice cream & 130 & 42.90 & 5 \\
Butter & 111 & 36.63 & 6 \\
Wagashi & 85 & 28.05 & 7 \\
\hline
\end{tabular}

Source: Field survey, 2001

$* 1=$ most patronized; and 12 = least patronized dairy product. The table shows the percentage of respondents who patronized the products, but not how much of each product consumed.

Dairy consumption expenditure and income level

As expected, the study revealed that consumption expenditure on dairy products increases with income (Figure 1). This finding is in consonance with economic theory, which posits that consumers in the higher income groups spend more on consumer goods due to high disposable income and hence high purchasing power. It is worthy of note that both theory and empirical evidence suggest that as income increases consumers spend relatively less proportion of their income on food. However, consumption patterns shift from basic calories to more processed and nutritive but expensive food products (e.g. protein-rich dairy products). A study by Mullins et al. (1994) revealed three principal determinants of dairy consumption among coastal Kenya households. These are cultural traditions, household income and household location. The study revealed that income appears to predominate over household location as a determinant of dairy consumption.

Figure 2 depicts the effect of income on household expenditures on tinned evaporated milk, yoghurt and raw fresh milk. Expenditure on tinned evaporated milk and yoghurt increases with increasing level of income. However, expenditure on raw fresh milk was found to decrease with increasing level of income. The implication is that as income increases, consumers switch from raw fresh milk consumption to the consumption of processed dairy products like yoghurt and evaporated milk. However, the finding is in sharp contrast to the situation in Kenya and the developed world where dairy consumers switch from processed dairy products to unprocessed or raw products when income rises (Seyoum, 1988). In East Africa cattle is common and it is reported that every household has at least one dairy cow; thus fresh milk is common and familiar to consumers. In the developed world, processing of raw fresh milk is done under hygienic conditions (Seyoum, 1988). In Ghana, like many developing countries, processing of fresh milk is perceived to be done under relatively unhygienic conditions; thus the fear of negative health risks associated with the consumption of the product is high among consumers who are located outside the 'zongos' where raw milk is common. 


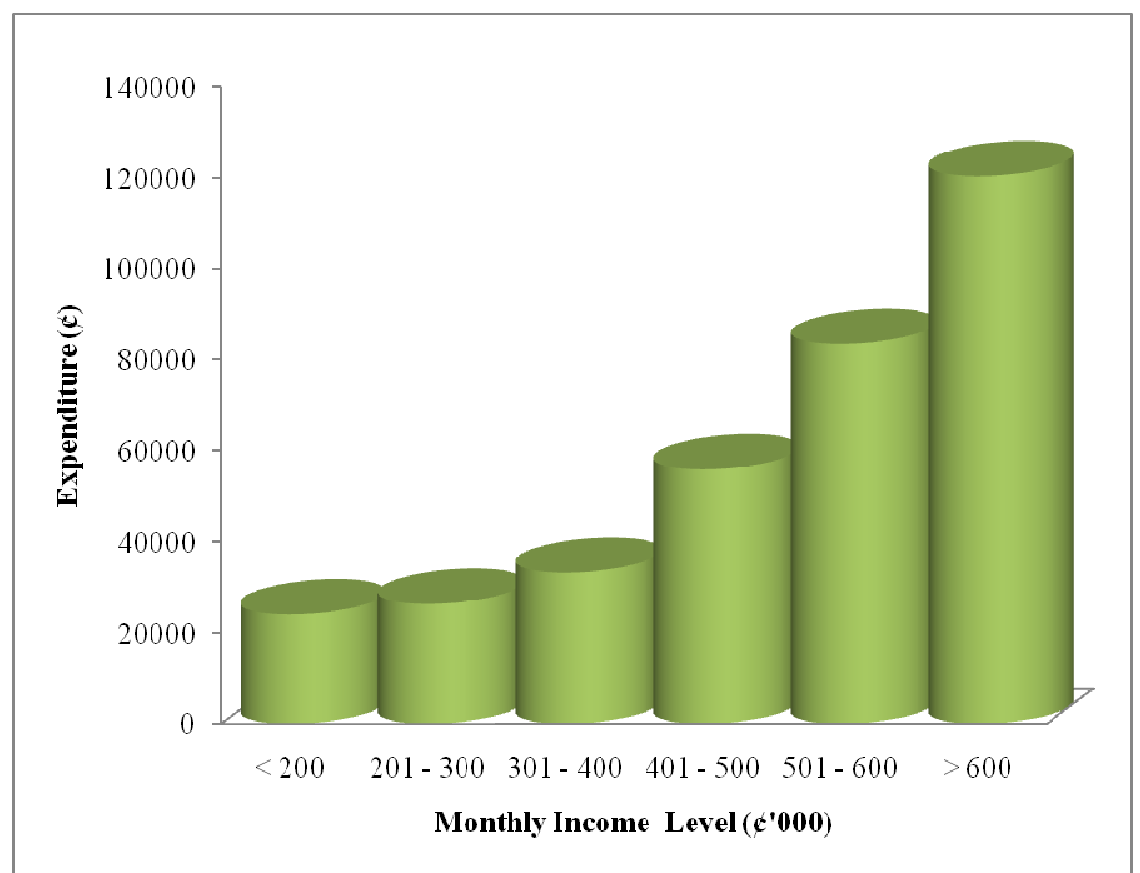

Source: Field survey, 2001

Figure 1: Average monthly dairy consumption expenditure by income group

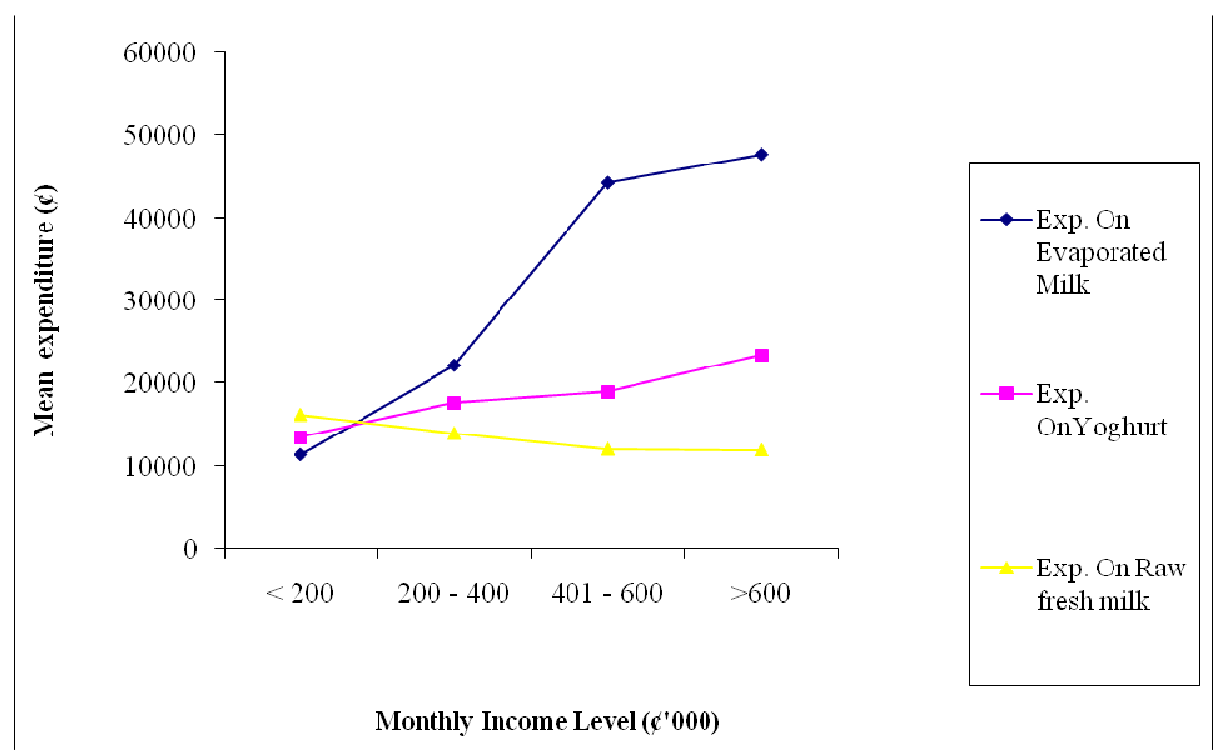

Source: Underlying data from field survey, 2001

Figure 2: Expenditure on selected dairy products by Income level 
Urbanization and Dairy consumption expenditure

Table 3 depicts the mean monthly expenditure on dairy products by degree of urbanization. The study revealed that expenditure made on dairy products by consumers in purely urban (metropolitan) and semi-urban areas are significantly different. The hypothesis of no difference between the expenditures made by urban and semi-urban consumers was rejected at the $1 \%$ level. The statistical test of difference gave Zvalue of 13.734 .

\section{Determinants of dairy consumption expendi- ture}

Aggregate dairy consumption expenditure model A double logarithmic function was fitted to the data obtained from the field, with total monthly dairy consumption expenditure on all dairy products as the dependent variable. Table 4 gives the model estimates and all variables in the model have been defined in the appendix. The study revealed that income level of consumer; distance to dairy product purchase point and the level of urbanization of consumer location are the factors that significantly influence the level of dairy con-

Table 3: Mean monthly dairy consumption expenditure by Level of urbanization

\begin{tabular}{lcc}
\hline Consumer location & Frequency $(\mathbf{N}=\mathbf{3 0 3})$ & Mean Expenditure $(\boldsymbol{k})$ \\
\hline Urban (Metropolitan) Area & 249 & $35,254.75$ \\
Semi-urban Area & 54 & $20,027.27$ \\
\hline
\end{tabular}

Z-test Z=13.734 (degree of freedom: 302; Sig @ 1\%-two tailed)

Source: Field Survey, 2001

Table 4: Aggregate Dairy Consumption expenditure model estimates

\begin{tabular}{llll}
\hline Variable & Coefficient & t & Probability \\
\hline Constant & $3.152^{* *}$ & 2.819 & 0.000 \\
LOG INC (Y) & $0.422^{* *}$ & 4.134 & 0.000 \\
LOG DIST & $0.103^{*}$ & 2.081 & 0.031 \\
RESP AGE & -0.016 & -0.270 & 0.352 \\
SEX & -0.036 & -0.639 & 0.529 \\
EDU & 0.035 & 0.526 & 0.956 \\
RLGN & -0.041 & -0.611 & 0.102 \\
TRIBE & -0.043 & -0.698 & 0.376 \\
UBL & $-0.477 * *$ & -6.184 & 0.000 \\
YGUT & 0.098 & 1.741 & 0.518 \\
RAWMILK & -0.014 & -0.215 & 0.347 \\
EVAPMILK & 0.053 & 0.885 & 0.491 \\
POWDMILK & 0.023 & 0.420 & 0.884 \\
WAGASHI & -0.080 & -1.530 & 0.543 \\
STOREMILK & -0.0087 & -0.159 & 0.628
\end{tabular}

Dependent Variable: Monthly household dairy consumption expenditure;

$R=0.784, R^{2}=0.615$, Adj. $R^{2}=0.596$, Std. Error $=0.398 ; F=36.70, D F=242$ (Significant at $1 \%$ )

$*=$ Significant at $5 \% ; * *=$ Significant at $1 \%$ 
sumption expenditure. The positive sign of the coefficients of income level and distance from home to dairy product purchase point, which is consistent with a priori expectations and economic theory, is an indication of a direct (positive) relationship between these variables and household dairy consumption expenditure level.

The magnitudes of the exponents of income level $(0.42)$ and distance from home to dairy product purchase point $(0.10)$ are also in consonance with economic theory. Because these exponents or elasticities are fractions (i.e. $0<\beta i<1$ ), consumption expenditure on dairy products increases at a decreasing rate for increasing levels of income and distance from home to purchase point. This satisfies Engel's law, which is suggestive of diminishing marginal expenditure on dairy products for each unit increase in income level. The study revealed that consumers in purely urban centers (metropolitan areas) spend $ф 4,256$ $(42.6 \%)$ more on dairy products than their counterparts in semi-urban areas. This result is in conformity with the finding by Jaffee and Motton
(1995) that consumers in urban centers of Kenya spend more on dairy products than rural and semi -urban consumers. This state of affairs can principally be attributed to high disposable income (and for that matter high purchasing power) in urban areas (Lu Hsu and Yu-Tso, 2006).

\section{Raw fresh milk consumption expenditure model} Table 5 shows the estimated model for raw fresh milk. The regression results show that price of raw fresh milk, price of evaporated milk, income level, distance from consumer's homestead to purchase point and religion are the factors which significantly influence raw fresh milk expenditure at the 5\% level. The elasticity of raw fresh milk expenditure with respect to own price was found to be unity. Income level was found to be negatively related to the consumption expenditure on raw fresh milk. The negative exponent (- 0.100) implies that for a $10 \%$ increase in income level, consumption expenditure on raw fresh milk decreases but at a declining rate of $1 \%$. This means that consumers shift from raw fresh milk to the consumption of processed dairy products when

Table 5: Raw Fresh Milk Consumption expenditure estimates

Dependent variable: Monthly household expenditure on raw fresh milk; $R=0.901, R^{2}=0.812$, Adjusted $R^{2}=0.800$, Standard Error $=0.146 . F$-Ratio $=33.072(D F=26) ;$ significant at $1 \%$

\begin{tabular}{lllc}
\hline Variable & Coefficient & \multicolumn{1}{c}{ t } & Probability \\
\hline Constant & $2.838^{* *}$ & 5.712 & 0.000 \\
LOG INC (Y) & $-0.100^{* *}$ & -4.271 & 0.001 \\
LOG FS & -0.259 & -1.006 & 0.391 \\
LOG RMP & $1.001^{* *}$ & 7.184 & 0.000 \\
LOG YP & 0.351 & 1.063 & 0.428 \\
LOG EvPmP & $0.442^{* *}$ & 2.131 & 0.014 \\
UBL & 0.102 & 0.836 & 0.096 \\
TRB & 0.116 & 0.977 & 0.127 \\
RGN & $-0.285^{*}$ & -2.065 & 0.036 \\
EDU & -0.102 & -0.739 & 0.225 \\
DIST & $-0.050^{* *}$ & -2.607 & 0.013 \\
\hline
\end{tabular}

$*=$ Significant at $5 \% ; * *=$ Significant at $1 \%$

NB: All variables have been defined in the Appendix. 
income increases. The negative sign of the income elasticity of raw fresh milk consumption expenditure may suggest that raw fresh milk is an inferior commodity in Ghana. The inferiority of raw fresh milk may be attributed to the negative consumer perception about the product, which stems from what some consumers consider as unhygienic methods of preparation and bad odour of the product.

The price of tinned evaporated milk, a close substitute of raw fresh milk, was found to have a significant positive influence on raw fresh milk expenditure level. The cross elasticity was found to be 0.44 . This observation could have serious implication for the local dairy industry. If the government implements policies that encourage the use of imported raw materials for industrial production of processed dairy products such as tinned evaporated milk it would impact negatively on the demand for raw fresh milk in Ghana. When such policies are sustained, local dairy production will suffer. Distance from home to point of purchase was found to be negatively related to the expenditure on fresh milk. Muslims were found to spend $\phi 1,334$ more on raw fresh milk than consumers belonging to other religions. This observation is not surprising since milk production is high among Muslims; raw fresh milk production centers and purchase points identified in the study were mostly located in Muslimdominated communities like Aboabo in Kumasi and Nima in Accra. Even though tribe was found to be insignificant in the model, intuitively it appears that the ethnic background of Muslims (mostly northerners) is associated with cattle rearing and thus fresh milk consumption.

\section{Consumption Expenditure Model for Tinned Evaporated Milk}

The regression results show that price of evaporated milk, income level, urbanization of consumer location; and raw fresh milk consumption significantly influence consumption expenditure on tinned evaporated milk at the 5\% level (Table $6)$. The elasticity of evaporated milk expenditure with respect to own price was found to be close to

Table 6: Evaporated Milk Consumption expenditure estimates

Dependent variable: Monthly household expenditure on evaporated milk; $R=0.883, R^{2}=0.779$, Adjusted $R^{2}=0.780$, Standard Error $=0.204, F$-ratio $=42.930(d f=114)$; significant at $1 \%$

\begin{tabular}{lllc}
\hline Variable & Coefficient & t & Probability \\
\hline Constant & $3.400^{* *}$ & 16.244 & 0.000 \\
LOG INC (Y) & $0.541^{* *}$ & 14.112 & 0.000 \\
LOG EvPmP & $1.021^{* *}$ & 20.178 & 0.000 \\
LOG YP & 0.101 & 1.715 & 0.413 \\
LOG FS & -0.257 & -1.643 & 0.522 \\
UBL & $-0.442^{* *}$ & -8.418 & 0.000 \\
RMC & $-0.154^{* *}$ & -2.504 & 0.011 \\
RGN & $0.111^{*}$ & 2.025 & 0.034 \\
TRB & -0.072 & -1.282 & 0.205 \\
EDU & 0.012 & 0.207 & 0.512 \\
\hline
\end{tabular}

$*$ Significant at $5 \% ; * *=$ Significant at $1 \%$

NB: All variables have been defined in the Appendix. 
unity, suggesting a constant marginal expenditure on the product for each percentage increase in the price of tinned evaporated milk. Consumer income was also found to be positively related to consumption expenditure on tinned evaporated milk. Consumers of raw fresh milk spend about $\phi$ 3,580 less on evaporated milk than nonconsumers of raw fresh milk. Consumers of raw fresh milk might use evaporated milk as a substitute in the absence of raw fresh milk. It is therefore not surprising that they spend less on tinned evaporated milk. On the average, urban consumers spend $\phi 6,950$ more on evaporated milk than consumers in the semi-urban areas. Muslims were found to spend $\phi 3,243$ less on evaporated milk than their Christian counterparts. Since Muslims were found to spend more on raw fresh milk, it is logical to suggest that they supplement raw milk consumption with that of evaporated milk. As a result, their expenditure on evaporated milk must be less.

\section{CONCLUSIONS AND RECOMMENDATIONS}

Most dairy product consumers are low-income earners.

The principal determinants of aggregate expenditure on dairy products were found to be income level of household head, level of urbanization of consumer location and distance from home to dairy product purchase point. Expenditure on raw fresh milk was found to be significantly influenced by income level of household head, own price, price of evaporated milk, religion and distance to fresh milk purchase point. Income level, own price, urbanization, religion and raw fresh milk consumption are the determinants of household expenditure on evaporated milk. There is a positive relationship between expenditure level on tinned evaporated milk and income level.

However, there is an inverse relationship between expenditure on raw fresh milk and income level. Generally, the elasticity of dairy consumption expenditure with respect to own price was found to be unity.
The elasticity of dairy expenditure with respect to income level and price of substitute products was less than unity.

In line with the finding that fresh milk is an inferior commodity in Ghana, vigorous consumer education to erase the negative perception about the product is recommended. Also, more hygienic methods of raw milk preparation, presentation and storage should be considered. It is recommended that marketing agents and producer sellers should explore the possibility of locating more dairy product selling points in communities dominated by low income earners to boost consumer demand for dairy products.

\section{REFERENCES}

Asenso-Okyere, W.K., Asante, F.A., and Nube, M. (1997). "Determinants of Health \& Nutritional status of children in Ghana" - In Sustainable Food Security in W/Africa; Klunder Academic publishers, Pp. 198-200.

Deaton, A. S. and Muellbauer, J. (1980). An Almost Ideal Demand System. The American Economic Review 7(33): 12-32.

Jaffee, S. and Morton, J. (1995). Marketing Africa's High-Value Foods; Comparative Experiences of an Emergent private sector, edited by Jaffee and Morton, Pp 225-227.

Jerome, M.E. and Perreault, D. W. (1993). Applications in Basic Marketing; Clippings from the popular Business press, 1993-1994 edition, IRWIN press, Pp 69, 72, 76.

Lu, H. J. and Yu-Tso, L. (2006). Consumption and attribute perception of fluid milk in Taiwan, Journal of Nutrition \& Food Science, 36 (3): $177-182$.

Mullins, G., Rey, B., Nokoe, S. and Shapiro, B. (1994). A research methodology for characterizing dairy product consumption systems, Market-Oriented Smallholder Dairying Research - International Livestock Center for Africa (ILCA) Working Document 2, Pp15 30, ILCA Publication, Addis Ababa . 
Nutrition Society (2002). Consumption of dairy products in the European Prospective, Investigation into Cancer and Nutrition (EPIC) cohort, In: Hjartåker, A. \& Lagiou, A. eds., Public Health Nutrition, Published on behalf of the Nutrition Society by CABI Publishing, New York, Pp 1-2.
Seyoum, S. (1988). Patterns of Consumption of Dairy products in West Africa, ILCA Working Document No. 11, Pp 11 - 38.

Walton, G. M. and Wykoff, F. C. (1998). Understanding Economics Today, $6^{\text {th }}$ edition, IRWIN/McGraw-Hill Publishers, Pp. 53-57.

\begin{tabular}{|c|c|}
\hline VARIABLE & DEFINITION \\
\hline LOG & Logarithm to base ten \\
\hline $\mathrm{Y}$ & Income level of household head \\
\hline YP & Yoghurt Price \\
\hline RMP & Raw milk price \\
\hline EvPmP & Tinned evaporated milk price \\
\hline FS & Family size \\
\hline DIST & Distance from home to purchase point (in Kilometers) \\
\hline RESP AGE & Age of respondent $(<30$ years $=0$, Otherwise $=1)$ \\
\hline SEX & Gender of respondent $($ Male $=0$, Female $=1)$ \\
\hline EDU & Educational level of respondent $($ Literate $=0$, Illiterate $=1)$ \\
\hline RGN & Religion of respondent (Muslim =0, Christian =1) \\
\hline TRIBE & Tribe of respondent $($ Northerner $=0$, Southerner $=1)$ \\
\hline UBL & Urbanization level of consumer location $($ Urban $=0$, Semi-urban $=1)$ \\
\hline YGUT & Yoghurt consumption $($ No $=0$, Yes $=1)$ \\
\hline RAWMILK & Raw milk consumption $($ No $=0$, Yes $=1)$ \\
\hline EVAPMILK & Evaporated milk consumption $(\mathrm{No}=0, \mathrm{Yes}=1)$ \\
\hline POWDMILK & Powdered milk consumption $(\mathrm{No}=0, \mathrm{Yes}=1)$ \\
\hline WAGASHI & Wagashi consumption $(\mathrm{No}=0, \mathrm{Yes}=1)$ \\
\hline STOREMILK & Storage of dairy products $($ No $=0$, Yes $=1)$ \\
\hline
\end{tabular}

